\title{
Up-date on neuro-immune mechanisms involved in allergic and non-allergic rhinitis*
}

\author{
Laura Van Gerven ${ }^{1,2}$, Guy Boeckxstaens ${ }^{3}$, Peter W. Hellings ${ }^{1,2}$ \\ Department of Otorhinolaryngology, Head \& Neck Surgery, University Hospitals Leuven, Leuven, Belgium \\ Laboratory of Experimental Immunology, Catholic University of Leuven, Leuven, Belgium \\ Department of Gastroenterology, University Hospitals Leuven, Leuven, Belgium
}

Rhinology 50: 227-235, 2012

DOI: 10.4193/Rhino.11.152

*Received for publication:

July 13, 2011

Accepted: January 21, 2012

\section{Summary}

Non-allergic rhinitis (NAR) is a common disorder, which can be defined as chronic nasal inflammation, independent of systemic lgE-mediated mechanisms. Symptoms of NAR patients mimic those of allergic rhinitis (AR) patients. However, AR patients can easily be diagnosed with skin prick test or allergen-specific lgE measurements in the serum, whereas NAR patients form a heterogeneous group and are difficult to diagnose because of an extensive list of different phenotypes, all varying in severity, underlying etiology and type of inflammation. Characterization of those phenotypes, mechanisms and management of NAR represents one of the major unmet needs in the field of allergic and non-allergic diseases. This review aims at providing a comprehensive overview of the state of the art in classifying the NAR patients and focuses on the neuro-immune mechanisms involved in allergic and non-allergic rhinitis, including reflections on the pathophysiology and the currently available treatment options.

Key words: non-allergic rhinitis, idiopathic rhinitis, capsaicin, neuro-immune mechanisms, nasal hyperreactivity, treatment, pathophysiology

\section{Introduction}

Chronic rhinitis represents a common condition affecting up to $30 \%$ of the Western population ${ }^{(1,2)}$. Patients with persistent rhinitis form a heterogeneous group when it comes to severity of symptoms, underlying etiology and inflammation ${ }^{(2)}$. In an attempt to take into consideration the pathophysiological mechanisms, rhinitis can be classified simplistically into allergic rhinitis, infectious rhinitis and non-allergic non-infectious rhinitis, comprising a large group with rhinitis of known and unknown origin. Indeed, up to $50 \%$ of patients with non-allergic non-infectious rhinitis do not have a clear etiology underlying their symptoms and are defined as idiopathic rhinitis (IR). In addition, combined phenotypes may occur, referred to as 'mixed' rhinitis ${ }^{(3)}$. According to the ARIA document, terms like 'vasomotor rhinitis' should be replaced by IR, as vasomotor mechanisms are ill defined and not always involved in this disease.

The definition of IR in a subgroup of non-allergic non-infectious rhinitis is largely based on exclusion criteria, i.e. the absence of clinical signs of infection and sensitization to inhalant allergens demonstrated by skin prick test (SPT) results or blood analysis of allergen-specific IgE. Symptoms of IR include nasal secretions, nasal obstruction, sneezing and nasal itching, and therefore mimic allergic rhinitis (AR). However, the majority of these patients do not respond well to anti-allergic treatment. Research on the underlying pathophysiology of IR has moved from autonomic neural disbalance with involvement of the unmyelinated sensory C-fibers containing various neuropeptides to a local inflammatory disorder with inflammation limited to the nasal mucosa with local IgE but without positive SPT and allergen-specific IgE in the blood, called 'entopy'. So far, entopy can only be demonstrated either by measuring allergen-specific $\lg E$ in the nasal cavity or by performing specific allergen provocations ${ }^{(4)}$. A subgroup of patients (30\%) with persistent rhinitis symptoms and negative SPT and blood analysis, showed a positive nasal response to specific allergen provocation. 
This review aims at providing a comprehensive overview of the state of the art in neuro-immune mechanisms involved in allergic and non-allergic rhinitis, including reflections on the pathophysiology and the currently available treatment options.

\section{Rhinitis classification}

Chronic rhinitis can clinically be classified into allergic, infectious and non-allergic non-infectious rhinitis ${ }^{(2)}$.

The diagnosis of allergic rhinitis is based on clinical symptoms with suspicion of allergy in combination with a positive skin prick test result or the presence of allergen-specific IgE in the serum. Rhinitis is defined as infectious rhinitis on a clinical base, i.e. when the nasal discharge is discolored and/or purulent. Microbiological detection of microorganisms is not mandatory for a diagnosis of infectious rhinitis. Infectious rhinitis is discriminated from rhinosinusitis (RS) on the basis of typical clinical features of RS like headache, facial pain, smell disorder on the one hand and mucosal pathology at the level of the osteomeatal unit on the other hand ${ }^{(5)}$.

The differential diagnosis of non-allergic non-infectious rhinitis is extensive, including non-allergic rhinitis with eosinophilia syndrome (NARES), also known as local allergy, rhinitis of the elderly, occupational rhinitis, drug induced rhinitis and hormonal rhinitis ${ }^{(6,7)}$ (Table 1$)$. The NARES group probably represents those patients with an allergen-specific immune response confined to the nasal mucosa and negative SPT ${ }^{(6,8)}$. The term 'entopy' has been proposed by Powe et al., to describe local allergy in individuals that are considered to be non-allergic ${ }^{(9)}$. The concept of local allergy in IR patients is both intriguing and controversial ${ }^{(10)}$. Some studies have demonstrated the presence of allergen-specific $\lg E$ in the nose ${ }^{(9)}$, a positive nasal allergen provocation test (NAPT) ${ }^{(4)}$ and inflammatory cells in a subset of IR patients ${ }^{(11)}$. Other studies do not confirm the involvement of inflammatory cells ${ }^{(12)}$ or the presence of a positive NAPT ${ }^{(13)}$. These seemingly conflicting observations may be the result of differences in nasal challenge techniques and more likely patient selection criteria. Whatsoever, Rondon et al., ${ }^{(4)}$ suggest that $35 \%$ of IR patients with a positive NAPT result have evidence of localized nasal specific IgE. Similar percentages are reported by Powe et al. ${ }^{(9)}$, demonstrating that $30 \%$ of IR patients have evidence of local allergy. As a consequence, approximately $70 \%$ of IR patients may present with symptoms originating from other mechanisms than allergen-driven initiation of an inflammatory cascade.

So far, IR remains a diagnosis per exclusionem in patients with mucosal nasal symptoms for which no explanation can be found. Clinical examination with rhinoscopia anterior and nasal endoscopy does not allow the discrimination between the different forms of non-allergic, non-infectious rhinitis.

\section{Nasal hyperreactivity}

Nasal hyperreactivity to various nonspecific stimuli like smoke, strong odours and other irritants is a common and characteristic feature of patients with persistent rhinitis, irrespective of an infectious, allergic or other etiology ${ }^{(14)}$.

Patients with allergic rhinitis usually complain of airway hyperreactivity to non-allergic stimuli both in upper as well as lower airways, generally considered to be a direct result of allergic airway inflammation ${ }^{(15)}$. Histologically, nasal hyperreactivity in AR has been shown to be associated with hyperinnervation of the nasal mucosa with increased expression of the neuropeptides calcitonin gene related peptide (CGRP) and Substance $P$ (SP) in periglandular nerve fibers (a sign of neuronal hyperactivity) ${ }^{(16)}$. Interestingly, AR and IR patients show the same level of mucosal hyperinnervation, suggesting a neuro-inflammatory involvement in both inflammatory nasal conditions. In a study of Braat et al. on pollutional and meteorological factors, IR patients seemed to be more sensitive to minor fluctuations in weather conditions compared to controls ${ }^{(17)}$. In contrast to cold temperatures, humidity or humidity changes was surprisingly less important in the induction of nasal symptoms ${ }^{(17)}$.

Until recently, the most common diagnostic test for measuring nasal hyperreactivity was the nasal histamine provocation, similar to the routinely performed bronchial histamine challenge for evaluation of bronchial hyperreactivity ${ }^{(18)}$. During nasal histamine provocation, increasing doses of histamine $(0.125,0.25,0.5,1,2$ and $4 \mathrm{mg} / \mathrm{ml})$ are applied on the nasal mucosa and measurements of nasal cross-sectional diameter or flow start after 1 minute of provocation and continue for 4 minutes. In addition to nasal histamine provocation, Cold Dry Air (CDA) nasal provocation has proven to be an effective tool in quantifying nasal hyperreactivity ${ }^{(19)}$. In 1998, Braat et al. demonstrated that CDA provocations were superior to nasal histamine provocations in discriminating IR patients from healthy controls ${ }^{(18)}$. Sensitivity for CDA was $87 \%$ compared with $100 \%$ for histamine, but, specificity was $71 \%$ for CDA and $0 \%$ for histamine. However, more studies on CDA nasal provocation studies are warranted to confirm the validity of this technique and elaborate it as a novel diagnostic tool in rhinology clinic. At present, there is no commercially available CDA device that can be used in clinical practice or for experimental purposes, and the reported studies on CDA have utilized home-made devices. There is now growing consensus about the usefulness of such a technique in daily practice, as nasal hyperreactivity often remains undiagnosed and cannot be taken into account in clinical trials evaluating the effects of current treatments of rhinitis.

\section{Innervation of the nasal mucosa}

Neural regulation in the upper airways is maintained by the sympathetic (adrenergic) and the parasympathetic (cholinergic) ner- 


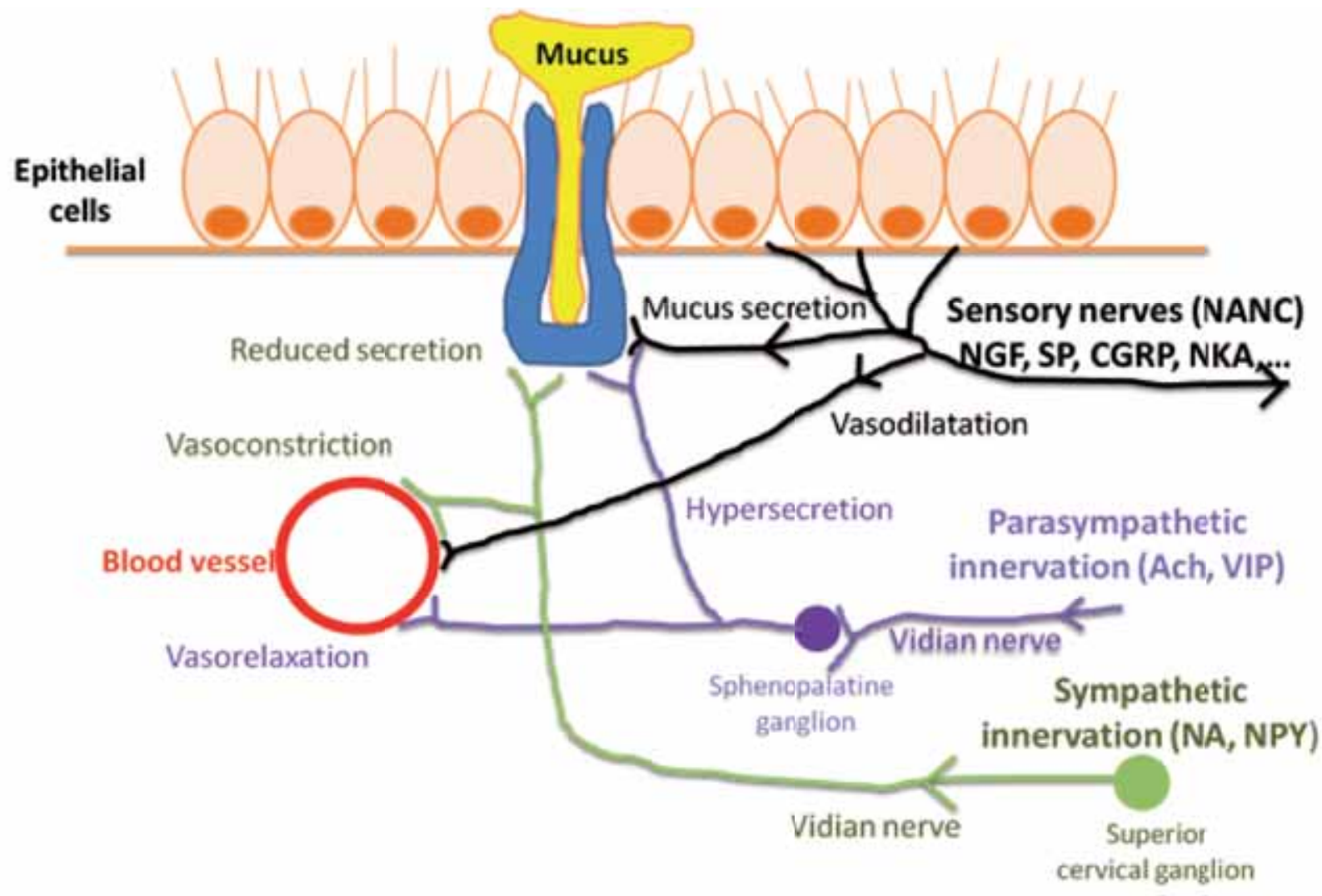

Figure 1. Innervation of the nasal mucosa.

vous systems (Figure 1), which innervate and interact in the nasal mucosa to regulate epithelial, vascular and glandular processes in particular. The sympathetic nerve fibers innervate mainly the vascular structures and to a lesser extent the secretory glands, where they release norepinephrine and neuropeptide Y (NPY) to cause predominantly vasoconstriction and a decrease in nasal secretion ${ }^{(20,21)}$. Parasympathetic fibers innervate both the blood vessels and the exocrine (seromucous and serous) glands of the nasal mucosa, of which glands appear to be more densely innervated. Those nerve fibers release predominantly acetylcholine and neuropeptide transmitters such as vasoactive intestinal peptide (VIP), which increase nasal secretion and induce vasorelaxation leading to nasal congestion under extreme conditions (22). VIP mainly acts through VPAC1 and VPAC2 receptors leading to glandular secretion. Under normal conditions the sympathetic nervous system is dominant ensuring vascular tone.

Several decades ago, the presence of intraepithelial and perivascular nonadrenergic noncholinergic (NANC) sensory nerve fibers was demonstrated in the human nasal mucosa ${ }^{(23)}$. These mainly unmyelinated sensory $C$-fibers contain various neuropeptides including Substance $P(S P){ }^{(24)}$, calcitonin gene related peptide (CGRP) ${ }^{(25)}$, neurokinin A and $B$ (NKA and NKB) ${ }^{(24)}$ which can be released by unspecific stimuli. In conjunction with the parasympathetic neurons, sensory (NANC) nerves play an essential role in protective nasal clearing reflexes such as sneezing, mucus production and congestion in response to noxious stimuli. These sensory neurons are receiving increasing attention as they are abundantly present and considered to be responsible for the release of neuropeptides in IR ${ }^{(26)}$, murine naso-bronchial ${ }^{(15)}$ and human naso-ocular ${ }^{(2)}$ interactions in allergic airway disease.

\section{Neuro-immune interactions in AR}

At present, the pathophysiology of allergic rhinitis is well known from an immunologic point of view. After binding of allergens to the allergen-specific IgE molecules on the surface of resident mast cells in the nasal mucosa and cross-linking of the FcEreceptor I, mast cells degranulate and release a wide array of pro-inflammatory mediators in sensitized individuals. Mediators like histamine, proteases, prostaglandin (PG)-D2 and leukotriens (LT)-C4 initiate an immune reaction that causes an early and late immune reaction with attraction of granulocytes like eosinophils to the location of allergen deposition. Activated mast cells and other cells of the immune system release pro-inflammatory mediators such as interleukin (IL)-1, IL-4, IL-5, tumor necrosis factor (TNF)- $\alpha$ and interferon (INF)- $\gamma$, which all contribute to the inflammatory spectrum of AR. In addition to these immune mediators, neurogenic peptides are also involved in this process (Figure 2 ). Inflammatory mediators stimulate the afferent sensory nerve 


\section{IgE-mediated pathway}

\section{Neurogenic pathway}

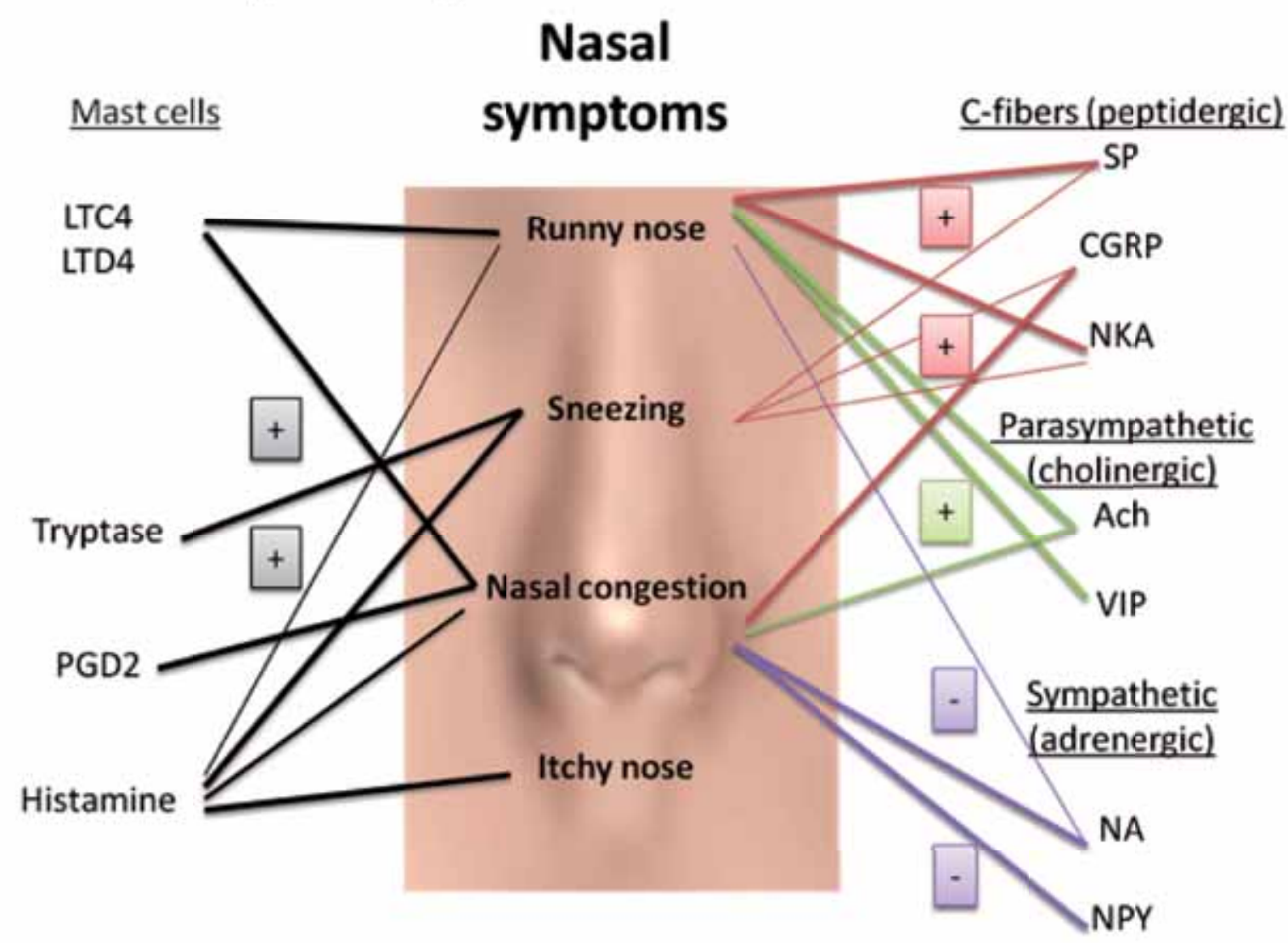

Figure 2. Pathways inducing nasal symptoms.

endings in the nasal mucosa. Activated nerve endings release neurotrophins (nerve growth factor (NGF), brain derived growth factor (BDGF) and different neuropeptides, like SP, NKA and NKB and CGRP ${ }^{(27)}$. SP and NKA/B are also called 'tachykinins'. Tachykinins are inactivated by endopeptidases (type 24.11) present in several nasal tissue cells ${ }^{(28,29)}$.

Neurotrophins were initially known for their primary activity, i.e. the growth of peripheral and central nerves. In the mean time, it has become evident that neurotrophins have a variety of immunomodulatory effects on non-neuronal cells including eosinophils and mast cells (neurotrophin receptors present: trkA-C and p75), which also produce neurotrophins (neuronal feedback mechanisms) ${ }^{(30,31)}$. NGF also targets nociceptive fibers leading to increased SP content and dendrite sprouting. Increased levels of NGF have been reported both in serum as well as in nasal lavage fluid of allergic individuals ${ }^{(32)}$. Interestingly, nasal allergen provocation further up-regulated increased NGF in nasal lavage in atopic patients, but not in controls. Additionally, nasal BDNF expression was significantly increased after allergen provocation in $A R^{(33)}$.
The neuropeptides SP and NKA are both released by afferent nerves upon activation, and bind their NK1 and NK2 receptor respectively, present on epithelial and endothelial cells. Activation of these receptors results in glandular activation, leukocyte recruitment and activation of different immune cells. CGRP release results in vasodilatation upon binding to its receptor on endothelial cells. Besides stimulated afferent nerves, different studies have demonstrated that immune cells like eosinophils, neutrophils and dendritic cells are also a source of tachykinins such as SP ${ }^{(34)}$. Mast cells are not a source of SP, but express the NK1 receptor. Forsythe et al. demonstrated neuroimmuneinteraction within the human lung ${ }^{(35)}$. The activation of mast cells, eosinophils, sensory nerve endings and epithelial cells is responsible for the entire spectrum of symptoms, characteristic for AR (Figure 3). Okamoto et al. showed that SP upregulates mRNA for the pro-inflammatory cytokines IL-1 $\beta$, IL-3, IL-5, IL-6, TNF- $\alpha$ and IFN- $\alpha$ in the human nasal mucosa, which is an additional stimulus to allergic inflammation ${ }^{(36)}$. The long-term effects of SP on human mast cell expression of the FcE-receptorl was investigated by McCary et al., who showed a SP-mediated downregulation of receptor expression ${ }^{(37)}$. 


\section{Release of mediators}

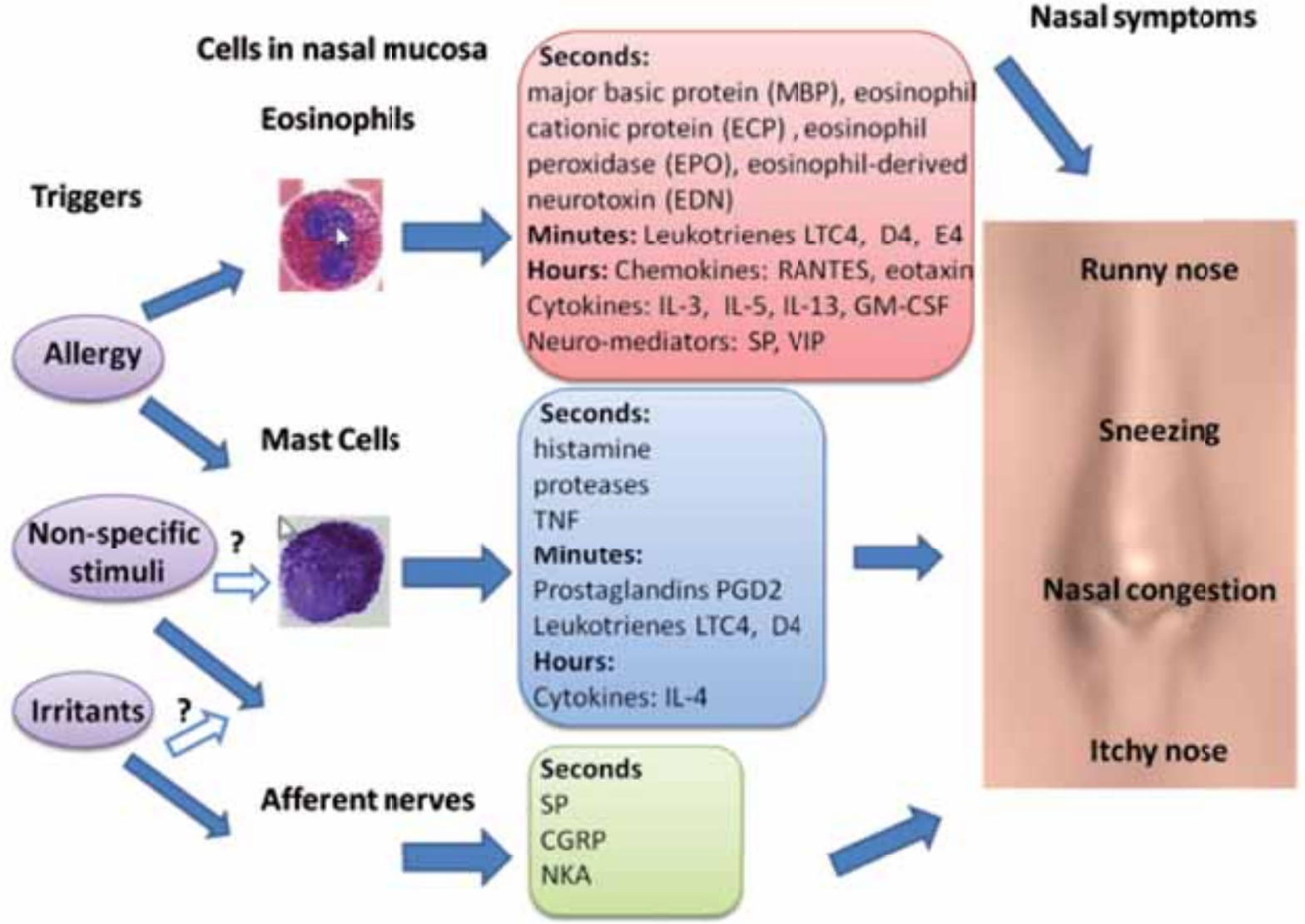

Figure 3. Triggers and cells involved in inducing rhinological symptoms in AR and IR patients.

Few reports examined the effects of anti-allergic agents on neuropeptides. Shinoda et al., showed a decrease in SP concentration in nasal lavage fluid in allergic patients with seasonal rhinitis after intake of oral antihistamines ${ }^{(38)}$. Recently, Schäper et al., showed significantly lower baseline levels of SP after intranasal Fluticasone propionate treatment (14 days treatment) in nasal lavage fluid of patients with persistent allergic rhinitis ${ }^{(39)}$. This effect was accompanied by an improvement in the clinical symptoms. Different mechanisms were proposed to contribute to this decreased release of neuropeptides caused by intranasal steroids. Corticosteroids can down-regulate tachykinin receptors and neuropeptides synthesis in neurons and in other immune cells ${ }^{\left({ }^{(0)}\right)}$. Additionally, corticosteroids are able to up-regulate the synthesis of neuropeptide-degrading enzymes (endopeptidases type 24.11) ${ }^{(41)}$. Besides the neuropeptides, other short amino acid peptides like endothelins ( 21 amino acids) can play a role in the induction of symptoms in AR since the expression of endothelins is enhanced in glands and inflammatory cells in chronic inflammation and endothelin-1 induces the secretion of proinflammatory mediators in human nasal mucosa. However, more studies are needed in order to determine the real importance of this endothelin cascade in nasal inflammation ${ }^{(42)}$.

\section{Neuro-immune interactions in IR}

As the name suggests, the etiology of IR remains largely unknown. Several mechanisms have been postulated to explain the pathophysiology of IR. The two most plausible hypotheses are non-lgE- mediated inflammatory responses and/or neurogenic responses.

Inconsistent data have been published on the non-IgE-mediated inflammatory responses as mentioned before. Powe et al., demonstrated an increased number of epithelial activated mast cells, increased mucosal eosinophils and increased $\lg \mathrm{E}^{+}$cells in the nasal airways of IR patients ${ }^{(11)}$, which could not be confirmed by the groups of Van Rijswijk and Blom et al. ${ }^{(12,43)}$. The major difficulty in comparing the few studies published on this topic is the inconsistency in defining this patient group. NARES patients for example were not excluded in Powe's study and can explain the discrepancy between reports.

Recently, more evidence for neurogenic mechanisms involved in IR was obtained. Activation of the sensory C-fibers of peptidergic neurons can lead to local release of neuropeptides (antidromic release) in the human nasal mucosa and thus can primarily trigger symptoms of $I R$, similar to AR (Figure 2). This 
Table 1. Differential diagnosis of non-allergic non-infectious rhinitis.

Nonallergic rhinitis with eosinophilia syndrome (NARES) / Local

Allergy

Drug induced rhinitis

Hormonal rhinitis

Rhinitis of the elderly

Occupational rhinitis

Idiopathic rhinitis (e causa ignota)

hypothesis was corroborated by Lacroix et al., who reported an increased concentration of neuropeptides in a group of IR patients ${ }^{(44)}$. Similarly, Heppt et al., demonstrated a denser innervation of SP-containing sensory nerves in the nasal mucosa of IR patients ${ }^{(45)}$. Similar observations are reported in occupational rhinitis and drug induced rhinitis ${ }^{(46)}$. In some forms of drug induced rhinitis, neurogenic mechanisms have been proposed to play a crucial role ${ }^{(47)}$. For example, drugs such as guanethidine and methyldopa, principally sympatholytic agents, elicit their effects by down-regulation of the sympathetic nervous system, leading inevitably to symptoms of nasal congestion (47).

\section{Current treatment options for IR}

Intranasal corticosteroids (INS)

Today, as recommended by current guidelines, almost all patients with severe persistent rhinitis, independent of the underlying pathophysiology, are initially treated with intranasal corticosteroids (INS) ${ }^{(48)}$. Due to their potent anti-inflammatory potential, INS have a good clinical efficacy in nasal inflammation. However, clinicians will agree that not all patients with IR benefit from INS. Indeed, inconsistent results have been reported on the efficacy of INS in the treatment of IR patients, suggesting that inflammation may not be an important underlying mechanism in all patients. In studies showing a favorable effect of INS in IR patients ${ }^{(49)}$, NARES patients/patients with local lgE were not excluded, possibly explaining their positive results. In contrast, Blom et al., showed only limited or no benefit of INS in IR ${ }^{(50)}$.

\section{Antihistamines}

Two double-blind placebo-controlled trials have been published showing a therapeutic effect of azelastine nasal spray in IR patients with nasal obstruction and or rhinorrhea when treated for 15 or 21 days ${ }^{(51,52)}$. In spite of their efficacy, the precise mode of action remains to be elucidated. The older antihistamines often have some anticholinergic side effects possibly contributing to the therapeutic effect.

\section{Ipratropium bromide}

Ipratropium bromide (IB) is an anticholinergic drug, effective in reducing the severity and duration of the rhinorrhoea in $I R^{(53)}$.
IB is considered a safe molecule and is recommended for use in the elderly with bilateral nasal secretions as presenting symptom and without other endonasal pathology.

\section{Nasal application of botulinum toxin A (BTA)}

Nasal hypersecretion due to IR can often not be treated sufficiently by conventional medication ${ }^{(50)}$. In a placebo-controlled study, Rohrbach et al. showed that BTA applied with a sponge brought subjective long-lasting reduction of hypersecretion in $46 \%$ of the patients with therapy-resistant IR ${ }^{(54)}$. The fact that not all patients treated reported a subjective improvement, can be explained by the knowledge that acetylcholine does not play a major role in all patients with nasal hypersecretion. Baraniuk et al. postulated that BTA also influenced other neuropeptides in nasal secretion ${ }^{(26)}$, explaining the observed reduction of nasal secretion by BTA in some of the ipratropium bromide resistant patients ${ }^{(25)}$.

\section{Capsaicin (Table 2, table of all published data)}

Since 1991, several studies have demonstrated that repeated nasal applications of capsaicin have a therapeutic effect in 70\% - $80 \%$ of IR patients ${ }^{(55-57)}$. Most studies reported a long-lasting relief of symptoms ranging from 6 to 9 months ${ }^{(43)}$. Capsaicin, the pungent ingredient of the plants of the genus Capsicum is known for its ability to activate/desensitize a specific subset of primary sensory C- and A- $\delta$ fibers ${ }^{(58)}$. Recently, Davies et al., showed that capsaicin can initiate TRPV1-dependent cell death in neuron-like cells ${ }^{(59)}$. This finding of an apoptosis-like process triggered by capsaicin can explain the long-lasting effects of capsaicin treatment in IR patients. Capsaicin binds the TRPV1 receptor, also known as 'pain receptor,' present on these C-fibers. TRPV1 is part of the superfamily of transient receptor potential (TRP) cation channels. TRPV1 is highly selective for capsaicin and other vanilloid-like compounds. In addition, TRPV1 is activated by acidic $\mathrm{pH}$ and temperatures $>$ $42^{\circ} \mathrm{C}^{(60)}$. This intriguing receptor family appears to respond to an amazing variety of environmental stimuli, including noxious irritants, environmental pollutants and temperature. Activation of TRPV1 by capsaicin can cause release of neuropeptides (antidromic release) and subsequently rhinorrhea, nasal 


\begin{tabular}{|c|c|c|c|}
\hline Study: Capsaicin - IR & Publication & Subject & Conclusions \\
\hline 1. Lacroix et al. & $\begin{array}{l}\text { Clinical and Experimental } \\
\text { Allergy, } 1991\end{array}$ & $\begin{array}{l}\text { Improvement of symptoms of non-allergic } \\
\text { chronic rhinitis by local treatment with } \\
\text { capsaicin. }\end{array}$ & $\begin{array}{l}\text { - Capsaicin nasal spray is an effective treat- } \\
\text { ment for IR patients }\end{array}$ \\
\hline 2. Riechelmann et al. & HNO, 1993 (in German) & $\begin{array}{l}\text { Treatment of perennial non-allergic rhin- } \\
\text { opathy with capsaicin. }\end{array}$ & $\begin{array}{l}\text { - Capsaicin is an effective treatment for IR } \\
\text { patients }\end{array}$ \\
\hline 3. Blom et al. & $\begin{array}{l}\text { Clinical and Experimental } \\
\text { Allergy, } 1997\end{array}$ & $\begin{array}{l}\text { Intranasal capsaicin is efficacious in non- } \\
\text { allergic, non-infectious rhinitis. A placebo } \\
\text { controlled study. }\end{array}$ & $\begin{array}{l}\text { - Capsaicin has no effect on inflammatory } \\
\text { mediators } \\
\text { - Inflammatory cells do not play a major } \\
\text { role in the pathogenesis of NANIPER }\end{array}$ \\
\hline 4. Sanico et al. & $\begin{array}{l}\text { Clinical and Experimental } \\
\text { Allergy, } 1998\end{array}$ & $\begin{array}{l}\text { Comparison of nasal mucosa responsive- } \\
\text { ness to neural stimulation in NAR and AR: } \\
\text { effects of capsaicin nasal challenge. }\end{array}$ & $\begin{array}{l}\text { - Non-allergic rhinitis is not characterized } \\
\text { by increased responsiveness of capsaicin- } \\
\text { sensitive nerve fibres; while allergic } \\
\text { rhinitis is marked by hyperresponsiveness } \\
\text { manifested as increased albumin leakage } \\
\text { in nasal fluids. }\end{array}$ \\
\hline 5. Blom et al. & $\begin{array}{l}\text { Clinical and Experimental } \\
\text { Allergy, } 1998\end{array}$ & $\begin{array}{l}\text { The long-term effects of capsaicin aqueous } \\
\text { spray on the nasal mucosa }\end{array}$ & $\begin{array}{l}\text { - Capsaicin significantly improves nasal } \\
\text { symptomatology in NANIPER patients } \\
\text { without affecting cellular homeostasis or } \\
\text { overall neurogenic staining }\end{array}$ \\
\hline 6. Van Rijswijk et al. & Allergy, 2003 & $\begin{array}{l}\text { Intranasal capsaicin reduces nasal hyper- } \\
\text { reactivity in IR: a double-blind randomized } \\
\text { application regimen study. }\end{array}$ & $\begin{array}{l}\text { - Intranasal capsaicin is safe } \\
\text { - } 5 \text { applications on } 1 \text { day is as effective as } 5 \\
\text { treatments in } 2 \text { weeks }\end{array}$ \\
\hline 7. Ciabatti et al. & $\begin{array}{l}\text { Acta Oto-Laryngologica, } \\
2009\end{array}$ & $\begin{array}{l}\text { Intranasal Capsicum spray in IR: a rand- } \\
\text { omized prospective application regimen } \\
\text { trial. }\end{array}$ & $\begin{array}{l}\text { - Local capsicum oleous nasal spray reduces } \\
\text { the frequency of IR symptoms vs controls. } \\
\text { - No side effects were recorded }\end{array}$ \\
\hline
\end{tabular}

blockage and sneezing (Figure 2). This initial aggravation of nasal complaints is indeed reported by patients receiving nasal capsaicin application.

The hypothesis that hyperreactivity of the sensory, unmyelinated C-fibers is the underlying pathophysiology in IR can offer an explanation for the beneficial effect of this treatment. Lacroix et al., reported an increased concentration of neuropeptides in a group of IR patients, which support this hypothesis ${ }^{(44)}$. However, Blom et al., could not find reduction of those sensory C-fibers in the nasal mucosa in IR patients after successful capsaicin treatment ${ }^{(43)}$.

In placebo-controlled studies, no therapeutic effect for capsaicin was found in patients with house dust mite AR patients ${ }^{(61,61)}$. This observation indirectly supports the idea that neurogenic inflammation is secondary to the lgE-mediated pathway in AR, whereas the efficacy of capsaicin in IR may be due to predominance or dysfunction of the peptidergic system in the absence of nasal inflammation.

Until know, no further research has been done on TRPV1 receptors on other structures of the nasal mucosa. Mast cells and epithelial cells in the skin of prurigo nodularis patients express TRPV1 suggesting that capsaicin is not solely interacting with sensory nerve fibers and thus other mechanism of action may be involved ${ }^{(63)}$. Better insight in the mechanism of action of capsaicin is mandatory to develop more specific and more potent agents to treat.

\section{Conclusion}

At present, we are still at the beginning of understanding the heterogeneity of the different pathophysiological mechanisms involved in NAR. The neural mechanisms involved in NAR and AR have been an underappreciated area of research so far. Understanding the role of neuropeptides is mandatory for the elaboration of novel treatment options. Following the currently available treatments for NAR, new therapeutic approaches consist of the development of substances that intervene in the neurogenic inflammatory processes and inhibit the synthesis/ release of neuropeptides.

\section{Conflict of interest}

None 


\section{References}

1. Bousquet J, Khaltaev N, Cruz AA, et al. Allergic Rhinitis and its Impact on Asthma (ARIA) 2008 update (in collaboration with the World Health Organization, GA(2)LEN and AllerGen). Allergy. 2008; 63 Suppl 86: 8-160.

2. Bousquet J, Fokkens W, Burney P, et al. Important research questions in allergy and related diseases: nonallergic rhinitis: a GA2LEN paper. Allergy. 2008; 63: 842-853.

3. Bernstein JA. Allergic and mixed rhinitis: Epidemiology and natural history. Allergy Asthma Proc. 2010; 31: 365-369.

4. Rondón C, Romero JJ, López S, et al. Local IgE production and positive nasal provocation test in patients with persistent nonallergic rhinitis. J. Allergy Clin. Immunol. 2007; 119: 899-905.

5. Fokkens W, Lund V, Mullol J. EP3OS 2007: European position paper on rhinosinusitis and nasal polyps 2007. A summary for otorhinolaryngologists. Rhinology. 2007; 45: 97-101.

6. Rondón C, Canto G, Blanca M. Local allergic rhinitis: a new entity, characterization and further studies. Curr Opin Allergy Clin Immunol. 2010; 10: 1-7.

7. Bachert C. Persistent rhinitis - allergic or nonallergic? Allergy. 2004; 59 Suppl 76: 11-5; discussion 15.

8. Jacobs RL, Freedman PM, Boswell RN. Nonallergic rhinitis with eosinophilia (NARES syndrome). Clinical and immunologic presentation. J Allergy Clin Immunol. 1981; 67: 253-262.

9. Powe DG, Jagger C, Kleinjan A, Carney AS, Jenkins D, Jones NS. "Entopy": localized mucosal allergic disease in the absence of systemic responses for atopy. Clin Exp Allergy. 2003; 33: 1374-1379.

10. Forester JP, Calabria CW. Local production of IgE in the respiratory mucosa and the concept of entopy: does allergy exist in nonallergic rhinitis? Ann Allergy Asthma Immunol. 2010; 105: 249-55; quiz 256-258.

11. Powe DG, Huskisson RS, Carney AS, Jenkins D, Jones NS. Evidence for an inflammatory pathophysiology in idiopathic rhinitis. Clin Exp Allergy. 2001; 31: 864-72.

12. van Rijswijk JB, Blom HM, KleinJan A, Mulder PGH, Rijntjes E, Fokkens WJ. Inflammatory cells seem not to be involved in idiopathic rhinitis. Rhinology. 2003; 41: 25-30.

13. Wierzbicki DA, Majmundar AR, Schull DE, Khan DA. Multiallergen nasal challenges in nonallergic rhinitis. Ann Allergy Asthma Immunol. 2008; 100: 533-537.

14. Gerth van Wijk RG, de Graaf-in 't Veld C, Garrelds IM. Nasal hyperreactivity. Rhinology. 1999; 37: 50-55

15. Hens G, Raap U, Vanoirbeek J, et al. Selective Nasal Allergen Provocation Induces Substance P-mediated Bronchial Hyperresponsiveness. Am J Respir Cell Mol Biol. 2010; 44: 517-523.

16. Knipping S, Holzhausen HJ, Riederer A, Schrom T. Allergic and idiopathic rhinitis: an ultrastructural study. Eur Arch
Otorhinolaryngol. 2009; 266: 1249-1256

17. Braat JPM, Mulder PG, Duivenvoorden $\mathrm{HJ}$ Gerth Van Wijk R, Rijntjes E, Fokkens WJ. Pollutional and meteorological factors are closely related to complaints of non-allergic non-infectious perennial rhinitis patients: a time series model. Clin Exp Allergy. 2002; 32: 690-697.

18. Braat J, Mulder P, Fokkens W, van Wijk R, Rijntjes E. Intranasal Cold Dry Air Is Superior to Histamine Challenge in Determining the Presence and Degree of Nasal Hyperreactivity in Nonallergic Noninfectious Perennial Rhinitis. Am J Respir Crit Care Med. 1998; 157: 1748-1755

19. Togias AG, Naclerio RM, Proud D, et al. Nasal challenge with cold, dry air results in release of inflammatory mediators. Possible mast cell involvement. J Clin Invest. 1985; 76 : 1375-1381

20. Baraniuk JN, Castellino S, Lundgren JD, et al. Neuropeptide Y (NPY) in human nasal mucosa. Am J Respir Cell Mol Biol. 1990; 3: 165-173.

21. Baraniuk JN, Silver PB, Kaliner MA, Barnes PJ. Neuropeptide $Y$ is a vasoconstrictor in human nasal mucosa. J Appl Physiol. 1992; 73:1867-1872.

22. Baraniuk JN, Lundgren JD, Okayama M, et al. Vasoactive intestinal peptide in human nasal mucosa. J Clin Invest. 1990; 86: 825-831.

23. Lundblad L, Lundberg JM, Brodin E, Anggård A. Origin and distribution of capsaicin-sensitive substance P-immunoreactive nerves in the nasal mucosa. Acta Otolaryngol. 1983; 96 (5-6): 485-493.

24. Baraniuk JN, Lundgren JD, Okayama M, et al. Substance $P$ and neurokinin $A$ in human nasal mucosa. Am J Respir Cell Mol Biol. 1991; 4:228-236.

25. Baraniuk JN, Lundgren JD, Goff J, et al. Calcitonin gene-related peptide in human nasal mucosa. Am J Physiol. 1990;258 (2 Pt 1): L81-88.

26. Baraniuk JN, Kaliner M. Neuropeptides and nasal secretion. Am J Physiol. 1991; 261 (4 Pt 1): L223-235.

27. Barnes PJ. Neurogenic inflammation in the airways. Respiration Physiology. 2001; 125 (1-2): 145-154.

28. Baraniuk JN, Merck SJ. Neuroregulation of human nasal mucosa. Ann NY Acad Sci. 2009; 1170: 604-609.

29. Baraniuk JN, Merck SJ. New concepts of neural regulation in human nasal mucosa. Acta Clin Croat. 2009: 48: 65-73.

30. Scuri M, Samsell L, Piedimonte G. The role of neurotrophins in inflammation and allergy. Inflamm Allergy Drug Targets. 2010; 9: 173180.

31. Raap U, Braunstahl G-J. The role of neurotrophins in the pathophysiology of allergic rhinitis. Curr Opin Allergy Clin Immunol. 2010; 10: 8-13.

32. Bonini S, Lambiase A, Bonini S, et al. Circulating nerve growth factor levels are increased in humans with allergic diseases and asthma. Proc Natl Acad Sci USA. 1996; 93: 10955-10960
33. Sanico AM, Stanisz AM, Gleeson TD, et al. Nerve growth factor expression and release in allergic inflammatory disease of the upper airways. Am J Respir Crit Care Med. 2000; 161: 1631-1635.

34. Joos GF, Germonpré PR, Pauwels RA. Role of tachykinins in asthma. Allergy. 2000; 55: 321-337.

35. Forsythe P, McGarvey LP, Heaney LG, MacMahon J, Ennis M. Sensory neuropeptides induce histamine release from bronchoalveolar lavage cells in both nonasthmatic coughers and cough variant asthmatics. Clin Exp Allergy. 2000; 30: 225-232.

36. Okamoto Y, Shirotori K, Kudo K, et al. Cytokine expression after the topical administration of substance $P$ to human nasal mucosa. The role of substance $P$ in nasa allergy. J Immunol. 1993; 151: 4391-4398.

37. McCary C, Tancowny BP, Catalli A, et al. Substance $P$ downregulates expression of the high affinity IgE receptor (FcepsilonRI) by human mast cells. J Neuroimmunol. 2010; 220: 17-24.

38. Shinoda M, Watanabe N, Suko T, Mogi G, Takeyama M. Effects of anti-allergic drugs on substance $P(S P)$ and vasoactive intestinal peptide (VIP) in nasal secretions. Am J Rhinol. 1997; 11: 237-241.

39. Schäper C, Gustavus B, Koch B, et al. Effect of fluticasone on neuropeptides in nasal lavage in persistent allergic rhinitis. J Investig Allergol Clin Immunol. 2010; 20: 214-221.

40. Adcock IM, Peters M, Gelder C, Shirasaki $H$, Brown CR, Barnes PJ. Increased tachykinin receptor gene expression in asthmatic lung and its modulation by steroids. J Mol Endocrinol. 1993; 11: 1-7.

41. Graf K, Schäper C, Gräfe M, Fleck E, Kunkel G. Glucocorticoids and protein kinase C regulate neutral endopeptidase 24.11 in human vascular smooth muscle cells. Basic Res Cardiol. 1998; 93: 11-7.

42. Mullol J, Picado C. Endothelin in nasal mucosa: role in nasal function and inflammation. Clin Exp Allergy. 2000; 30: 172-177.

43. Blom HM, Severijnen LA, Van Rijswijk JB, Mulder PG, Van Wijk RG, Fokkens WJ. The long-term effects of capsaicin aqueous spray on the nasal mucosa. Clin Exp Allergy. 1998; 28: 1351-1358.

44. Lacroix JS, Kurt AM, Pochon N, Bretton C, Lundberg JM, Deshusses J. Neutral endopeptidase activity and concentration of sensory neuropeptide in the human nasal mucosa. Eur Arch Otorhinolaryngol. 1995; 252: 465-468.

45. Heppt W, Peiser C, Cryer A, et al. Innervation of human nasal mucosa in environmentally triggered hyperreflectoric rhinitis. J Occup Environ Med. 2002; 44: 924-929.

46. Shusterman D. Review of the upper airway, including olfaction, as mediator of symptoms. Environ Health Perspect. 2002; 110 Suppl 4: 649-653.

47. Varghese M, Glaum MC, Lockey RF. Druginduced rhinitis. Clin Exp Allergy. 2010; 40: 381-384. 
48. Brożek JL, Bousquet J, Baena-Cagnani CE, et al. Allergic Rhinitis and its Impact on Asthma (ARIA) guidelines: 2010 Revision. J Allergy Clin Immunol. 2010; 126: 466-476.

49. Lundblad L, Sipilä P, Farstad T, Drozdziewicz D. Mometasone furoate nasal spray in the treatment of perennial non-allergic rhinitis: a nordic, multicenter, randomized, double-blind, placebo-controlled study. Acta Otolaryngol. 2001; 121: 505-509.

50. Blom HM, Godthelp T, Fokkens WJ, KleinJan A, Mulder PG, Rijntjes E. The effect of nasal steroid aqueous spray on nasal complaint scores and cellular infiltrates in the nasal mucosa of patients with nonallergic, noninfectious perennial rhinitis. J Allergy Clin Immunol. 1997; 100 (6 Pt 1): 739-747.

51. Banov CH, Lieberman P. Efficacy of azelastine nasal spray in the treatment of vasomotor (perennial nonallergic) rhinitis. Ann Allergy Asthma Immunol. 2001; 86: 28-35.

52. Gehanno P, Deschamps E, Garay E, Baehre M, Garay RP. Vasomotor rhinitis: clinical efficacy of azelastine nasal spray in comparison with placebo. ORL J Otorhinolaryngol Relat Spec. 2001; 63: 76-81.

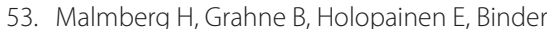
E. Ipratropium (Atrovent) in the treatment of vasomotor rhinitis of elderly patients. Clin Otolaryngol Allied Sci. 1983; 8:273-276.

54. Rohrbach S, Junghans K, Köhler S, Laskawi R. Minimally invasive application of botulinum toxin $\mathrm{A}$ in patients with idiopathic rhinitis Head Face Med. 2009; 5: 18

55. Lacroix JS, Buvelot JM, Polla BS, Lundberg JM. Improvement of symptoms of nonallergic chronic rhinitis by local treatment with capsaicin. Clin Exp Allergy. 1991; 21: 595-600.

56. Blom HM, Van Rijswijk JB, Garrelds IM Mulder PG, Timmermans T, Gerth van Wijk $R$. Intranasal capsaicin is efficacious in nonallergic, non-infectious perennial rhinitis. A placebo-controlled study. Clin Exp Allergy. 1997; 27: 796-801.

57. Ciabatti PG, D'Ascanio L. Intranasal Capsicum spray in idiopathic rhinitis: a randomized prospective application regimen trial. Acta Otolaryngol. 2009; 129: 367-371.

58. Holzer P. Capsaicin: cellular targets, mechanisms of action, and selectivity for thin sensory neurons. Pharmacol Rev. 1991; 43 : 143-201.

59. Davies JW, Hainsworth AH, Guerin CJ, Lambert DG. Pharmacology of capsaicin-, anandamide-, and $\mathrm{N}$-arachidonoyldopamine-evoked cell death in a homogeneous transient receptor potential vanilloid subtype 1 receptor population. $\mathrm{Br} J$ Anaesth. 2010; 104: 596-602.

60. Bessac BF, Jordt S-E. Breathtaking TRP channels: TRPA1 and TRPV1 in airway chemosensation and reflex control. Physiology (Bethesda). 2008; 23: 360-370
61. Gerth Van Wijk R, Terreehorst IT, Mulder PG, Garrelds IM, Blom HM, Popering S. Intranasal capsaicin is lacking therapeutic effect in perennial allergic rhinitis to house dust mite. A placebo-controlled study. Clin Exp Allergy. 2000; 30: 1792-1798.

62. Cheng J, Yang XN, Liu X, Zhang SP. Capsaicin for allergic rhinitis in adults. Cochrane Database Syst Rev. 2006; CD004460.

63. Ständer S, Moormann C, Schumacher M et al. Expression of vanilloid receptor subtype 1 in cutaneous sensory nerve fibers, mast cells, and epithelial cells of appendage structures. Exp Dermatol. 2004; 13: 129-139.

\section{Peter Hellings}

University Hospitals Leuven

Department of Otorhinolaryngology

Head \& Neck Surgery

Kapucijnenvoer 33

3000 Leuven

Belgium

Tel: + 32-16-332 342

Fax: + 32-16-343 835

E-mail: Peter.hellings@uzleuven.be

\section{ADVERTISEMENT}

19th
International Course in
Modern Rhinoplasty
Techniques \&
Symposium
'Nasal Valve Surgery'
October 24, 25 and 26, 2012
Department of Otorhinolaryngology-FPRS
Academic Medical Center of the
University of Amsterdam
The Netherlands
Teacher of honour:
Dr Minas Constantinides,
NYU Medical Center, New York, USA
Course director:
Dirk Jan Menger, MD
Tuition fee
complete course - Euro 1475,
(incl. dissection) FRESH FROZEN CADAVER
For further information contact:
Department of Otorhinolaryngology,
Academic Medical Center of the University of Amsterdam,
The Netherlands,
Email: M.B.vanhuiden @amc.uva.nl
Website: www.rhinoplastycourse.nl
In affiliation with the European Academy of Facial Plastic Surgery
The course is under the auspices of the ERS

